\title{
Kouno Fumiyo's Hi no tori ('Bird of the Sun') Series as a Documentary Manga: Memory and 3.11
}

' 3.11 ' is the name now commonly applied to the Triple Disaster of March 11, 2011, consisting of the Great East Japan Earthquake, tsunami, and nuclear meltdown at Fukushima Daiichi Nuclear Power Plant. In the years following this tragedy, those in the affected regions were determined that Japan and the world remember the disaster. The media, popular culture, and local signs enjoined the public to 'never forget' or to remember 3.11, Fukushima, and Tōhoku. Such insistence was not only understandable, but also likely necessary. Indeed, as German memory studies scholar Aleida Assmann's writings on the nature of active and passive memory remind us, forgetting is a natural process; remembering often requires effort (Assmann 2011: 334-7).

For several years after 2011, major bookshops in Japan featured special ' 3.11 corners' around the anniversary of the disaster. These 'corners' usually consisted of collections of fiction and nonfiction books related to the disaster. Months later, however, these ' 3.11 corners' had largely vanished from Tokyo bookshops, the titles previously contained within them finding new homes on shelves in other literary sections such as fiction, nonfiction, current fiction, and, notably, in the 'saigai' (disaster) section, a relatively small assortment of books on disasters including 9/11, the Chernobyl incident, and the Kobe Earthquake (Hanshin Awaji daishinsai). Visits to bookshops in coastal towns in the hisaichi (disaster areas) in Tōhoku painted a decidedly different picture: the ' 3.11 corners' were comprised of large sections of books occupying multiple shelves and tables, with 3.11-related books prominently displayed. In Kamaishi, a town hard hit by the disaster, a large sign still hangs in a local bookshop: 'Ichiban kowai no wa, füka suru koto' - 'what we fear most is the weathering of memories'. The expression ' $f u \overline{k a}$ ' can mean to forget, but it can also refer to the natural process of fading away - in this case of memory. Within the context of 3.11, füka is, on the one hand, an inevitable process; on the other, however, it is a force to be resisted, as it counters imperatives to remember the disaster and to keep it at the forefront of discourse.

Alongside the inevitable fading of memories that characterizes the aftermath of a disaster runs the related current of reconstruction $(f u k k \bar{o})$. ' $F u k k \bar{o}$ ' refers to the reconstruction of the devastated areas, including the rebuilding of homes, infrastructures, businesses, and communities; the term implies progress and forward momentum. At present, the reconstruction effort in the disaster-stricken areas continues apace, and most of the temporary structures (kasetsu jūtaku) have been replaced with permanent buildings. In the fall of 2019, the tsunamidevastated city of Kamaishi in Iwate prefecture, with a population of around 34,000, will host around 16,000 spectators for the Rugby World Cup. The event will be held in the Kamaishi Unosumai Memorial Stadium (Kamaishi Unosumai Fukkō Sutajiamu)i, built expressly for this world-class sporting event. Alongside the World Cup fervor and under the banner of $f u k k \bar{o}$, the town is reinventing itself and looking to its future whilst preserving memories of 3.11. Nationally, Japan is busily making preparations to host the 2020 Tokyo Olympics, and the memory of 3.11 is being obscured by the excitement of this global sports spectacle. In other words, although imperatives to remember amidst recovery remain strong in the recovering 
regions in Tōhoku, as Japan edges closer to the games and further away from the disaster, fears that 3.11 will be forgotten amidst a sense of 'Olympic amnesia' are not unfounded.

This inherent tension between the reflexive movement of memory and the forward movement of reconstruction - between $f \bar{u} k a$ and fukkō-lies at the heart of Hi no tori, a two-part manga series by well-known artist Kouno Fumiyo about life in the hisaichi in the aftermath of 3.11. Hi no tori first appeared as a serialized manga in the Nihon Bungeisha journal Shūkan Manga Goraku (Weekly Manga Goraku) between March 2012 and March 2014; it was published in book form in May 2014. The second volume, Hi no tori 2, was serialized in the same journal between March 2014 and January 2016 and published in book form in June 2016. The manga depicts a cockerel's search for his missing wife in the months and years following 3.11, documenting his physical movement through numerous towns in varying states of reconstruction in the disasterstricken areas. His four-year search takes him from coastal cities like Kamaishi to the heart of the exclusion zone in Fukushima. His visits to particular sites evoke memories - sometimes humorous and light-hearted, sometimes melancholy and bittersweet - of their life together. At first, the cockerel observes the disruption caused by the disaster: boats washed up into car parks; railway tracks severed by the tsunami that will never be rebuilt; damaged roads and train stations. As time passes, he is relieved to discover that the norms of daily life have largely resumed: trains running, traffic lights restored, roads and structures rebuilt.

Unlike most manga, Hi no tori does not consist simply of drawings and text; rather, it has an unusual formal structure that blurs the boundaries between fiction and nonfiction, demonstrating the flexibility of the medium. In addition to the cockerel's narrative and the drawings of sites in the hisaichi, the manga contains documentary information on the impact of the disaster and the progress of the reconstruction. This information is, for the most part, not conveyed through the perspective of the cockerel, but rather in the form of statistics. Moreover, at the end of Hi no tori 2 there is a seventeen-page long supplemental manga titled 'Chiisana sekai' (A Small World) that consists of drawings and a handwritten letter narrated from the perspective of a Uranium atom personified. 'She' tells the story of nuclear fission and how Uranium becomes Caesium 137, or radiocaesium, the radioactive isotope of Caesium, which was released into the environment by the meltdown at the Fukushima Daiichi Nuclear Power Plant. Kouno's manga, with its unusual layout, can thus be described as a composite of various elements: drawings, prose, poetry, statistical data, maps, and artist's commentary.

Both structurally and in terms of narrative content, $\mathrm{Hi}$ no tori is characterized by movement: between $f \bar{u} k a$ and $f u k k \bar{o}$ (forgetting and reconstruction), between past and present, and between sites in the hisaichi. Significantly, the formal structure of the manga depends on movement in other ways as well: between genres (fiction and nonfiction), between absence and presence, invisibility and visibility, and the reader's movement between the visual and textual components of the manga. This paper evaluates the Hi no tori series as a documentary manga and analyzes the movements invoked by its formal structure. It aims to better understand what is at stake — both aesthetically and ethically — in the manga's unique mode of representation. I will argue that as a documentary manga, the Hi no tori series employs the multiple possibilities the medium of comics engenders in order to bear witness not only to 3.11, but to its aftermath and, more precisely, to the uneasy spaces between the traumatic event itself and the present. 
In her discussion of 'comic-book histories', Tessa Morris-Suzuki highlights the potential of historical comics as transmitters of historical events: 'Their stark, dramatic images also have the power to burn themselves into our memories, influencing the way in which we see the present and re-remember the past' (Morris-Suzuki 2005: 164). Beginning with Nakazawa Keiji's Hadashi no Gen (Barefoot Gen, 1973-1985) ${ }^{\mathrm{ii}}$ and followed by Art Spiegelman's Maus: A Survivor's Tale (1980-1991), ${ }^{\text {iii }}$ comics have been employed to great effect as a medium for the representation of traumatic historical events. An autobiographical manga based loosely around the actual experiences of atomic bomb survivor, Nakazawa, in Hiroshima during the Second World War, Barefoot Gen is frequently hailed as the first nonfiction manga about historical trauma. Published several years later, Maus depicted Spiegelman interviewing his father about his experiences during the Holocaust, portraying events of the war in flashback. Spiegelman was awarded the Pulitzer Prize (Special Award in Letters) for Maus in 1992, thereby elevating the medium of comics to new critical heights. Continuing this trend, in 1996 Joe Sacco's twovolume graphic novel, Palestine, a ground-breaking piece of graphic journalism based on Sacco's experiences during a stay in the Gaza Strip and West Bank and several months of research, won the American Book Award. Sacco's work-including Footnotes in Gaza (2009), a graphic journalistic novel that uses official sources and testimonies to investigate two violent incidents that occurred during the Suez Crisis, and The Fixer: A Story from Sarajevo (2003), a graphic novel about the Bosnian War-represents a shift from the autobiographical approaches of Nakazawa and Spiegelman to a more journalistic approach. His work skilfully demonstrates the possibilities the medium of comics engenders; as comics scholar Hillary Chute has noted, Sacco '[...] offers a prime example of what comics today can do: he has reinvented a genre, comics journalism, that is now flourishing across the globe' (Chute 2017: 314).

Prior to Hi no tori, Hiroshima-born artist Kouno Fumiyo had addressed issues of historical trauma and memory in several of her earlier works. Best known amongst these is her fictional manga about the atomic bombing of Hiroshima, Yünagi no machi, sakura no kuni (Town of Evening Calm, Country of Cherry Blossoms, 2003-2004). The work consists of two separate but interconnected narratives that address the bomb and its impact on everyday life in the years that followed. Hi no tori represents a departure from Kouno's pre-existing manga oeuvre as well as from the work of both Nakazawa and Spiegelman. It is neither based on an autobiographical account of the disaster, nor is it presented in the familiar multiframe format commonly employed in Barefoot Gen, Maus, or Town of Evening Calm, Country of Cherry Blossoms. In fact, Hi no tori does not even provide an account of the disaster itself.

In a dialogue between Kouno and fellow manga artist Nishijima Daisuke published in a special edition of the journal Yuriika (Eureka) dedicated to the study of Kouno's works, the two discuss the unconventionality of Hi no tori as a manga. Nishijima points out that readers of Kouno's previous manga might find $\mathrm{Hi}$ no tori unsettling as it differs significantly from her other works. He even goes so far as to state that Hi no tori barely qualifies as a manga ('girigiri manga'), and then further suggests that it is less a manga than a picture, or perhaps an experiment at producing something like art (Kouno and Nishijima 2016: 41). Kouno points out that Hi no tori has been referred to as an 'irasuto essei' (illustrated essay), but that she herself describes it as a 'hito koma manga' (single scene manga ${ }^{\text {iv }}$ ). In the same edition of Eureka, Kimura Saeko refers to it as a 'tabi enikki' (illustrated travel diary) (Kimura 2016: 211). In evaluating Hi no tori as a documentary manga, Chute's observations on nonfiction comics prove instructive: '[...] comics 
as a medium places pressure on classifiability and provokes questions about the boundaries of received categories of narrative' (Chute, 2016: 1). The comments by Kouno, Nishijima, and Kimura demonstrate the unusual structure of $\mathrm{Hi}$ no tori, even within the medium of manga.

Both Hi no tori 1 and 2 begin with a table of contents (mokuji) that lists the sites visited by the cockerel in his search for his wife. Each chapter title clearly indicates the period of time that has elapsed since the disaster and the name of the town. For example, one chapter is titled 'Gokagetsugo no Kamaishi $\bullet$ Ötsuchi' ('Kamaishi and Ōtsuchi five months after'). The system of measuring time in both Hi no tori 1 and 2 establishes March 11, 2011 as a 'year zero', counting the months and years after 3.11 rather than using the conventional Gregorian or lunar calendar year to mark time. Unlike Barefoot Gen, Maus, or Town of Evening Calm, Country of Cherry Blossoms, which rely on techniques such as flashback and temporal shifts, Hi no tori progresses in chronological fashion.

The main body of both manga includes numerous chapters corresponding to particular locations affected by the disaster. The first page of each chapter consists of an amalgamation of pieces of information about the town: a map of Japan indicating the town's location, a hand drawing of a physical object from the region (souvenir or regional delicacy) and handwritten text describing it, and statistical data on the disaster [See Figure 1]. This incorporates information such as the magnitude of the earthquake and height of the tsunami in the particular town, losses of human lives and property, damage to property, and statistics on the progress of the reconstruction.

Each of these introductory pages is followed by several pages of hand-drawn ballpoint pen sketches portraying sites in the hisaichi town with the cockerel depicted somewhere in the scene. Kouno drew the sketches using photographs she took during her frequent trips to the hisaichi after 3.11. In an age where documentary photography in particular is frequently regarded as the most accurate mode for representing trauma, Kouno's hand drawings clearly demonstrate the emotive power of art. As Chute has noted: 'There are many examples of the visual-verbal form of comics, drawn by hand, operating as documentary and addressing history, witness, and testimony' (Chute 2016: 2). Embedded within each drawing are the place name and date written in the author's own hand, linking the artwork to the artist's personal experience. Importantly, Hi no tori primarily employs a single scene format rather than the multiframe format used in Maus, Barefoot Gen, and Town of Evening Calm, Country of Cherry Blossoms. The drawings of the hisaichi in Hi no tori are not enclosed within a bordered frame; rather, the drawings mostly blend into the surrounding space of the page. Or, to put it another way, they are 'framed' only insomuch as they are surrounded by the white space of the page. Kouno's borderless drawings allow the reader a more empathetic engagement with the scene depicted, as they are able to locate themselves within the scene unconstrained by boundaries or lines of demarcation.

Below the drawing of the scene in the hisaichi there is text which generally reflects the cockerel's words and thoughts. Occasionally, the text indicates a perspective other than that of the cockerel, for example, conversations overheard by him. Beside the text is a box titled 'Honjitsu no shokuji' (today's meal), which contains a drawing and description of what the cockerel had to eat that day. At the bottom of the page are notes from the artist offering context and insight to the scene depicted and the text. The artist's note, separated from the text and daily 
menu by a solitary line, comprises an important supplemental element. Here the artist makes her presence known in a formal way, offering commentary on the scene and providing local knowledge based on her experiences during her stay in the hisaichi; the notes provide the reader with information that is not accessible without the interlocutory voice of the artist herself.

At the end of both $\mathrm{Hi}$ no tori 1 and 2 there is a list of citations ([Hi no tori] inyo risuto), which identifies sources the author consulted for information regarding tsunami height, radiation levels, earthquake magnitude, etc. The list of citations is extensive, lending a decidedly scientific and statistical tone to the text as a whole. Notably, Kouno's Town of Evening Calm, Country of Cherry Blossoms also includes a list of citations at the end of the manga.

The unconventional structure of the Hi no tori manga series, as illuminated by the artist's notes and list of citations, incorporates what Gérard Genette would refer to as 'paratexts ${ }^{\text {iii', elements }}$ that somehow frame the main body of the text, impact our interpretation of the text, and imbue it with meaning. As Genette wrote of these paratextual elements: 'And although we do not always know whether these productions are to be regarded as belonging to the text, in any case they surround it and extend it, precisely in order to present it, in the usual sense of this verb but also in the strongest sense: to make present, to ensure the text's presence in the world, its "reception" and consumption in the form (nowadays, at least) of a book' (Genette 1997: 1). In Hi no tori, these paratextual elements profoundly affect the reader's experience of the manga. They include: a table of contents; pages with statistical information on the disaster and recovery; notes from the author; maps; a list of citations; and in Hi no tori 2, a supplementary manga. Genette characterized 'paratexts' as porous borders, spaces of transaction:

Indeed, this fringe, always the conveyor of a commentary that is authorial or more or less legitimated by the author, constitutes a zone between text and off-text, a zone not only of transition but also of transaction: a privileged place of a pragmatics and a strategy, of an influence on the public, an influence that - whether well or poorly understood and achieved - is at the service of a better reception for the text and a more pertinent reading of it (more pertinent, of course, in the eyes of the author and his allies) (Genette 1997: 2).

In Chute's discussion of Sacco's documentary comics, she highlights the potential of documentary comics as a form of presenting evidence: 'Comics makes a reader access the unfolding of evidence in the movement of its basic grammar, by aggregating and accumulating frames of information' (Chute, 2016: 2). Hi no tori presents the reader with both fictional elements (drawings and text) and documentary evidence in the form of statistical data and maps, each of which offers a different perspective on the disaster and reconstruction. These textual and paratextual elements in $\mathrm{Hi}$ no tori establish it as a manga that demands to be read as a hybrid consisting of both fiction and nonfiction. While the statistics presented on the first page of each chapter provide us with quantitative data, they cannot fully communicate the meanings associated with the disaster on a personal level. The drawings offer another dimension to the story, showing pictures of devastated areas and reconstructed areas alike. In the text accompanying the artist's drawings, the cockerel narrates his story of personal loss and the search for his wife. Although the cockerel's narrative is fictional, it nevertheless reflects the 
harsh reality experienced by survivors of 3.11 who lost loved ones, but were unable to verify their deaths. Hi no tori combines these various elements, resulting in a manga characterized by a fluid movement between the genres of fiction and nonfiction that does not allow either genre to dominate the narrative.

Hi no tori is most accurately described as a documentary manga, or perhaps even as a 'reportage manga' in the style of Sacco, largely considered the pioneer and master of this style of comic. Like Sacco's Palestine, Footnotes in Gaza, and The Fixer, Hi no tori has a journalistic aspect, as it is premised on the author's photographic documentation of and research conducted in the hisaichi. In fact, Kouno noted the importance of observing the state of the Tōhoku region after the disaster from an 'outside perspective' (sotogawa shiten) when drawing Hi no tori, and expressed her hope that the manga could serve as a record of what occurred at the time (Kouno 2016: 31-45). In her dialogue with Nishijima, Kouno points out that unlike Town of Evening Calm and Country of Cherry Blossoms, where as a Hiroshima resident, she had some kind of connection to the atomic bombings, she did not have a personal connection to Tôhoku, though her home in Tokyo was fairly close to the region. After the disaster, she travelled to Tôhoku herself, once every two or three months, taking photographs and bringing them back with her to Tokyo. She did not sketch the drawings on site, but rather used the photographs as well as her own research on local flora and other details when creating her work. Kouno describes the process as first composing the text and then deciding on the landscape (Kouno 2016: 31-45).

Alongside the fluctuation between the genres of fiction and nonfiction, Hi no tori also presents another type of movement: the act of consuming the narrative requires the reader to move visually between the components of the manga. The reader is presented with multiple pieces of information on the same page or on facing pages - drawings, prose, commentary, and statisticsand must navigate between them. As Eric J. Stainbrook has argued, comics are a composite text, and the reader plays an active role in its consumption: 'In struggling with the discourse situations presented in the comic, the reader must not only perceive and interpret the signs of the visual surface of the comics text, but must be able to perceive and interpret, or more exactly, to reconcile, the two lines of discourse in relation to each other' (Stainbrook 2003: 135). As he suggests, it is precisely through this movement between image and text that the reader locates meaning. Moreover, with Hi no tori, as the narrative does not consist of chronologically ordered panels, the reader has agency in determining the direction of flow in their experience of the manga. Chute has commented on the ethical issue of pacing when reading a work that addresses traumatic historical events such as war: 'In comics, the reader controls his or her own pace of consumption, unlike in a time-based medium such as film or video, in which a violent image might flit by, or occupy the screen for what feels like too long' (Chute 2017: 332). The experience of reading the manga is therefore a dynamic one, as readers are interpolated into the very act of reading.

The labour of the reader in piecing together the composite elements of the text operates in parallel to the labour of the cockerel, who continually invokes the memory of his wife, drawing our attention to both absence and presence in the narrative. In Multidirectional Memory: Remembering the Holocaust in the Age of Decolonization, Michael Rothberg, drawing on the work of Richard Terdiman and Dominick LaCapra, argues that memory should be regarded as something which is, first, alive and existing in the present and, second, results from action or labour (Rothberg 2009: 4-5). Hi no tori skillfully portrays the cockerel's struggle to preserve the memory of his wife not merely as a remnant of the past, but as something current. On each page, 
the cockerel continues his search, inquiring of those he meets if they have seen his wife or invoking some memory of her.

In one especially poignant sketch, the cockerel is pictured walking along the railway tracks in Minami-Sōma, near the center of the exclusion zone at Fukushima. The artist's explanatory note informs the reader that the tracks are no longer in use as a result of the nuclear meltdown at the nearby nuclear power plant. In the text, the cockerel addresses his wife directly: "Wife! I remember that the first time I held your claw I was excited and unexpectedly crowed out loud. Your claws were as hot as these here railway tracks under the burning sun" (Kouno: 2016, 49). Although the cockerel's recollection originates from his shared past with his wife, he ushers her into the present moment with the demonstrative 'kono' ('these here') to describe the physical sensation of warmth he feels on the railway tracks heated by the sun. The reader is made keenly aware of her presence in the current moment, emphasizing that contemporaneity of memories.

As Marianne Hirsch has argued in her study of generations of postmemory in relation to the trauma of the Holocaust, '[...] embodied journeys of return, corporeal encounters with place, do have the capacity to create sparks of connection that activate remembrance and thus reactivate the trauma of loss' (Hirsch 2012: 212). In Hi no tori, the cockerel narrates his wife into the present moment through the activation of memories, but, in doing so, he also highlights the aporia of memory: his words manifest her into the present, but on every page the reader is faced with her conspicuous absence. This dialogic movement between presence and absence brings to mind the thousands of lives lost in 3.11, who exist in the present only insofar as they are remembered.

Through the combination of drawings and text, comics have the power to transport readers to places they themselves cannot go and to render the invisible visible, and Hi no tori skillfully manipulates the potential of the medium for these dual purposes. For example, the manga devotes several pages to the cockerel's journey to sites near the exclusion zone in locations such as Fukushima and Minami-Sōma. These scenes remind the reader that the damage wrought by 3.11 and by the nuclear meltdown at the Fukushima Daiichi Nuclear Power plant in particular was by no means a singular event; its violence is ongoing. Rob Nixon emphasizes the necessity to rethink what he terms 'slow violence', that is, 'violence that occurs gradually and out of sight, a violence of delayed destruction that is dispersed across time and space, an attritional violence that is typically not viewed as violence at all' (Nixon 2011:2). Kouno's manga supplement to Hi no tori 2, 'Chiisana sekai' (A Small World) addresses 'slow violence' through its visual and textual representations of nuclear power and radiation. To accomplish this, the manga again exploits the potential of comics and its ability to move between perspectives in unusual ways; in this case, the manga supplement engages the element Uranium as narrator.

The structure of the supplement consists of hand-drawn pictures, a handwritten letter, and a multiframe manga at both the beginning and end. The narrative starts with a cartoon depiction of a feather, presumably fallen from the wings of our feathered protagonist, the cockerel himself, as he is depicted in the previous facing page. As the feather floats to the ground, the text encourages us to take a microscopically close examination of the feather. Inside the feather is a miniscule letter, and in the letter we are introduced to our narrator, Uranium personified. Manga artist Shiriagari Kotobuki also employed anthropomorphized representations of the chemical elements 
involved in the production of radioactive materials in his manga titled 'Kibē' ('Hope', 2011) . As Mary Knighton has argued of 'Hope', 'With this manga, Shiriagari makes visible and legible the invisible radioactive elements that, once identified and recognizable, provide strange comfort; made visible, they turn anxiety and paranoia into something "real" (Knighton 2013: $19)^{\mathrm{vi}}$. Through visualization and narration, both Shiragari and Kouno eloquently give meaning to the sentiments of Fukushima evacuees and those affected by the nuclear meltdown.

In the manga supplement to Hi no tori 2, Kouno demonstrates how the process of producing nuclear power unfolds, thereby helping to alleviate some of the anxiety associated with radiation as an unknown aggressor. Through letters and drawings, Uranium proceeds to tell the story of how atoms and molecules combine. For example, two molecules of hydrogen combine to form $\mathrm{H}_{2}$, a molecule of hydrogen; $\mathrm{H}_{2}$ then bonds to one atom of Oxygen to form water. The narrator then explains how Uranium 238 becomes Caesium 137 and how nuclear power is generated through nuclear fission, forming the radioactive isotope Caesium 137. This includes some rather sophisticated descriptions, and all the elements involved in the process are presented as personified cartoon-like characters. The last few drawings of 'Chiisana sekai' use these characters to accurately represent the complexities of the Uranium decay chain. Then, in the final frame, a large, ominous-looking dark bird bearing the characteristic markings of a phoenix flies above the nuclear power plant and perches on top of it. The text, a message from Uranium 238/Caesium 137, reads: 'Dewa itsuka. Kitto itsuka ne' ('See you someday. We'll surely meet someday') [See Figure 2]. It is signed: 'Yuraniumu 238 datta Seshiumu 137 yori' ('from Caesium 137, formerly Uranium 238') (Kouno 2016: 127). Here, the once benign Uraniumnow Caesium - takes on a more foreboding tone, implying the dispersal of invisible radioactive particles into the environment.

What is this mysterious bird in the final manga frame of 'Chiisana sekai'? Is it the Hi no tori of the title? First of all, it is worth mentioning that several of Kouno's other manga contain drawings of birds, and there are various birds portrayed throughout Hi no tori as well. The choice of a cockerel as a protagonist, however, is compelling, as in Japan the cockerel is often associated with forgetfulness. Hence, the manga portrays an avian protagonist who is by nature prone to forgetfulness, but whose memories persist despite the passage of time.

The kanji for Kouno's Hi no tori manga effectively translates as 'bird of the sun'. However, $\mathrm{Hi}$ no tori is also the title of a well-known and long-running manga series by the 'father of manga', Tezuka Osamu. Tezuka's Hi no tori (1967-1988) ${ }^{\text {vii }}$, uses the kanji for 'fire' (hi), so a literal translation would be 'fire bird' or 'bird of fire', and the title is rendered as 'Phoenix' in English, thus invoking phoenix-like birds of East Asian mythology, such as the fenghuang (hōo in Japanese). The Chinese phoenix can be referred to as the 'August cockerel' as it is sometimes used to replace the cockerel in the Chinese zodiac.

With respect to Kouno's Hi no tori, Kimura Saeko comments that the character used for ' $h i$ ' is not the character for 'fire', which means that ' $h$ i no tori' cannot refer to a phoenix - the mythological 'fire bird' that rises from the ashes after dying and is born again (Kimura 2016: 209). However, according to Morishita Hiroshi, although Kouno's Hi no tori uses the kanji for 'bird of the sun' rather than 'bird of fire', or 'phoenix', if you remove the book jacket of both the first and second volumes of Hi no tori, there is an ominous drawing of a phoenix depicted rising 
up into the sky (Morishita 2016: 246-7) [See Figure 3]. There are also suggestions of a large, mysterious bird appearing in the clouds in numerous drawings; they take the shape of wavy, indistinct, incomplete or non-continuous lines, bearing a resemblance to feathers or flocks of birds. In this way, Kouno renders the invisible violence of radiation from the nuclear power plant visible; like the radioactive particles released into the environment-seemingly nowhere but everywhere-the hi no tori is omnipresent throughout the text $\mathrm{t}^{\mathrm{vii}}$.

Morimatsu Akiko, Fukushima evacuee and key member of the Osaka-based advocacy group 'Thanks \& Dream: The Great Eastern Japan Earthquake \& Nuclear Evacuee Association', has addressed the United Nations and spoken widely of her experiences following the nuclear meltdown at Fukushima. She has discussed the invisible dangers of radioactivity in the wake of 3.11 , with particular attention to the ambiguity and anxiety experienced by evacuees in the aftermath resulting from a fundamental lack of information and guidance ${ }^{\mathrm{ix}}$. Today, Morimatsu continues to speak openly of the anxieties of Fukushima mothers like herself who, in the days after 3.11, had no choice but to drink water and to give it to their children, unaware at the time that it was contaminated with radiation (Morimatsu July 2019). In the wake of the disaster, the public and evacuees demanded information, but especially in the case of Fukushima, information not always forthcoming, and in many cases, it was either inaccurate or misleading. Beyond the immediate violence unleashed by the earthquake, tsunami, and nuclear meltdown, the slow violence of radiation and the lack of information are central to the nature of 3.11. Kouno's approach to Hi no tori, which combines fictional narrative with data seems particularly salient in consideration of the various challenges faced by Fukushima evacuees and the public after 3.11, who rightfully sought hard, scientific data when official narratives proved unreliable.

When considering what is at stake ethically in Kouno Fumiyo's representation of 3.11 in Hi no tori, Chute's observations on Sacco's documentary comics are informative. She points to the concept of 'inhabitation', which 'focuses attention on how people remember and reenact their own histories through drawing, and on how cartoonists endeavor to enter ethically into others' histories by materializing them on the page' (Chute 2016: 263). Hi no tori's unusual format fuses drawing, prose, narrative, and documentary reportage in an attempt to create an ethical representation of the disaster, one that addresses the unique conditions brought about by the Triple Disaster (earthquake, tsunami, and nuclear meltdown) and the anxiety faced by victims in its aftermath. The manga induces an empathetic response in readers who place themselves into the manga through the experience of 'inhabiting' the world of the pages, but also through the participatory act of reading the manga and the necessary labour involved in visually organizing its constituent elements. Kouno's manga builds on the lineage of manga representing traumatic historical events such as Barefoot Gen, Maus, and Town of Evening Calm, Country of Cherry Blossoms, but more closely resembles Sacco's documentary comics. It is perhaps best regarded as an evolution or adaptation of the documentary manga form to suit the challenges of representing 3.11. In its unique presentation of visual and textual elements, Hi no tori brings to bear the tools of documentary comics to negotiate the critical spaces in between fiction and nonfiction, past and present, presence and absence, and importantly, between forgetting ( $f \bar{u} k a)$ and reconstruction $(f u k k \bar{o})$. Linda Hutcheon has likened cultural adaptation to biological adaptation, arguing that it involves movement, a process of migration to different cultures and to different media, stating, 'stories adapt just as they are adapted' (Hutcheon 2013: 31). Kouno's Hi no tori constitutes an adaptation within the medium of comics, arguably a movement towards 
a more accurate representation of the complexity of 3.11, its constituent parts, and, crucially, its ongoing nature. 


\section{References}

Asia-Pacific Journal Feature. (2011). Japan's irradiated beef scandal. The Asia-Pacific Journal, 9(30), 1-4. Retrieved from https://apjjf.org/2011/9/30/Asia-Pacific-JournalFeature/3577/article.html

Assmann, A. (2011). From “canon and archive”. In J. K. Olick, V. Vinitzky-Seroussi, \& D. Levy (Eds.), The collective memory reader (pp. 334-337). New York: Oxford University Press.

Berndt, J. (2013). The intercultural challenge of the 'mangaesque'. In J. Berndt \& B. Kümmerling-Meibauer (Eds.), Manga's cultural crossroads (pp. 65-84). London, England: Routledge.

Berndt, J., \& Kümmerling-Meibauer, B. (Eds.). (2016). Manga's cultural crossroads. London: Routledge.

Chute, H. (2008). Comics as literature? Reading graphic narrative. PMLA, 123(2), 452-465. Retrieved from https://www.jstor.org/stable/25501865

Chute, H. L. (2016). Disaster drawn: Visual witness, comics, and documentary form. Cambridge, MA: Belknap Press of Harvard University Press.

Chute, H. L. (2017). Why comics ?: From underground to everywhere. New York, NY: Harper.

Chute, H. L., \& DeKoven, M. (2006). Introduction: Graphic narrative. MFS Modern Fiction Studies, 52(4), 767-782. https://doi.org/10.1353/mfs.2007.0002

Frid, M. J. (2011). Food safety: Addressing radiation in Japan's northeast after 3.11. The AsiaPacific Journal, 9(31), 1-9. Retrieved from https://apjjf.org/2011/9/31/Martin-J.Frid/3580/article.html

Fumio, K., \& Nishijima, D. (2016). Taidan: Katasumi yori ai wo komete. Eureka (Yuriika), 48$16,31-45$.

Genette, G. (2001). Paratexts: Thresholds of interpretation (J. E. Lewin, Trans.). Cambridge: Cambridge University Press.

Hirsch, M. (2012). The generation of postmemory: Writing and visual culture after the holocaust. New York: Columbia University Press.

Hutcheon, L. (2013). A theory of adaptation (2nd ed.). London: Routledge.

Ichitani, T. (2010). "Town of evening calm, country of cherry blossoms": The renarrativation of Hiroshima memories. Journal of Narrative Theory, 40(3), 364-390. Retrieved from JSTOR database. 
Kimura, S. (2016). Tegakari wo sagashiagunete watashitachi wa ondori no sugata wo sagasu - hi no tori wo yomu. Eureka (Yuriika), 48-16, 209-213.

Knighton, M. (2013). The sloppy realities of 3.11 in Shiriagari Kotobuki's manga しりあがり 寿がマンガで描く 3.11 のぞんざいな現実. The Asia-Pacific Journal: Japan Focus, 11(26), 1-35. Retrieved from https://apjif.org/2014/11/26/MaryKnighton/4140/article.html

Kouno, F. (2004). Yūnagi no machi sakura no kuni. Tokyo: Futabasha.

Kouno, F. (2014). Hi no tori. Tokyo: Nihon Bungeisha.

Kouno, F. (2016). Hi no tori 2. Tokyo: Nihon Bungeisha.

McCloud, S. (1994). Understanding Comics: Writing and Art. New York, NY: Harper Perennial.

Morimatsu, A. (2015). An Evacuation Memoir, May 2012. In A. Morimatsu (Author), Seeking safety: speeches, letters and memoirs by evacuees from the 2011 Fukushima daiichi nuclear disaster. (5th ed., pp. 17-25). London, UK: Red Kimono.

Morimatsu, A. (2015). Voice of women from the disaster area. In A. Morimatsu (Author), seeking safety: speeches, letters and memoirs by evacuees from the 2011 Fukushima daiichi nuclear disaster. (5th ed., pp. 2-4). London, UK: Red Kimono.

Morimatsu, A. (Presenter). (2019, July 26). Testimonial of a Fukushima evacuee. Lecture presented at Osaka City University, Osaka, Japan.

Morishita, H. (2016). Kouno Fumiyo zen tankōbon kaisetsu. Eureka (Yuriika), 48(16), 236-247.

Morris-Suzuki, T. (2005). The past within us: Media, memory, history. New York: Verso.

Nakazawa, K. (1994). 'Hadashi no gen’ jiden. Tokyo: Kyōiku Shiryō Shuppankai.

Nixon, R. (2013). Slow violence and the environmentalism of the poor. Cambridge, Mass.: Harvard University Press.

Olick, J. K., Vinitzky-Seroussi, V., \& Levy, D. (Eds.). (2011). The collective memory reader. New York: Oxford University Press.

Renan, E. (2011). Ernest Renan: From 'what is a nation?'. In J. K. Olick, V. Vinitzky-Seroussi, \& D. Levy (Eds.), The collective memory reader (pp. 80-83). New York: Oxford University Press.

Ricœur, P. (2010). Memory, history, forgetting (Paperback ed., [Nachdr.] ed.) (K. Blamey \& D. Pellauer, Trans.). Chicago, Ill. [u.a.]: Univ. of Chicago Press. 
Rosenbaum, R. (Ed.). (2015). Manga and the representation of Japanese history. London: Routledge.

Rosenbaum, R. (2015). The representation of Japanese history in manga [Introduction]. In R. Rosenbaum (Author), Manga and the representation of Japanese history. London: Routledge.

Rosenbaum, R. (2015). Towards a summation: How do manga represent history? In R. Rosenbaum (Ed.), Manga and the representation of Japanese history (pp. 251-258). London: Routledge.

Rothberg, M. (2009). Multidirectional memory: Remembering the Holocaust in the age of decolonization. Stanford, Calif.: Stanford University Press.

Sacco, J. (2001). Palestine. London, United Kingdom: Jonathan Cape.

Sacco, J. (2009). Footnotes in Gaza. London, United Kingdom: Jonathan Cape.

Shiriagari, K. (2011). Ano hi kara no manga. Tokyo: Entā Burein.

Spiegelman, A. (2009). Maus: A survivor's tale (Nachdr. ed.). London: Penguin Books.

Stainbrook, E. J. (2003). Reading comics: A theoretical analysis of textuality and discourse in the comics medium (Doctoral dissertation, Indiana University of Pennsylvania). Retrieved from Retrieved from https://ezproxyprd.bodleian.ox.ac.uk:7316/docview/305299727? accountid=13042

Tanaka, N. (2016). Kiroku suru koto no chikara: Zasshi/seikatsu/kōgengaku. Eureka (Yuriika), 48(16), 226-235.

Tokushū Kouno Fumiyo: Yünagi no machi, sakura no kuni kono sekai no katasumi ni bōrupen kojiki kara hi no tori e. (2016). Tokyo: Seidosha. 
Figure 1: Fumiyo Kouno. Hi no tori, 2014. Comic. Page 4. (c) Fumiyo Kouno/NIHONBUNGEISHA "HINO-TORI".

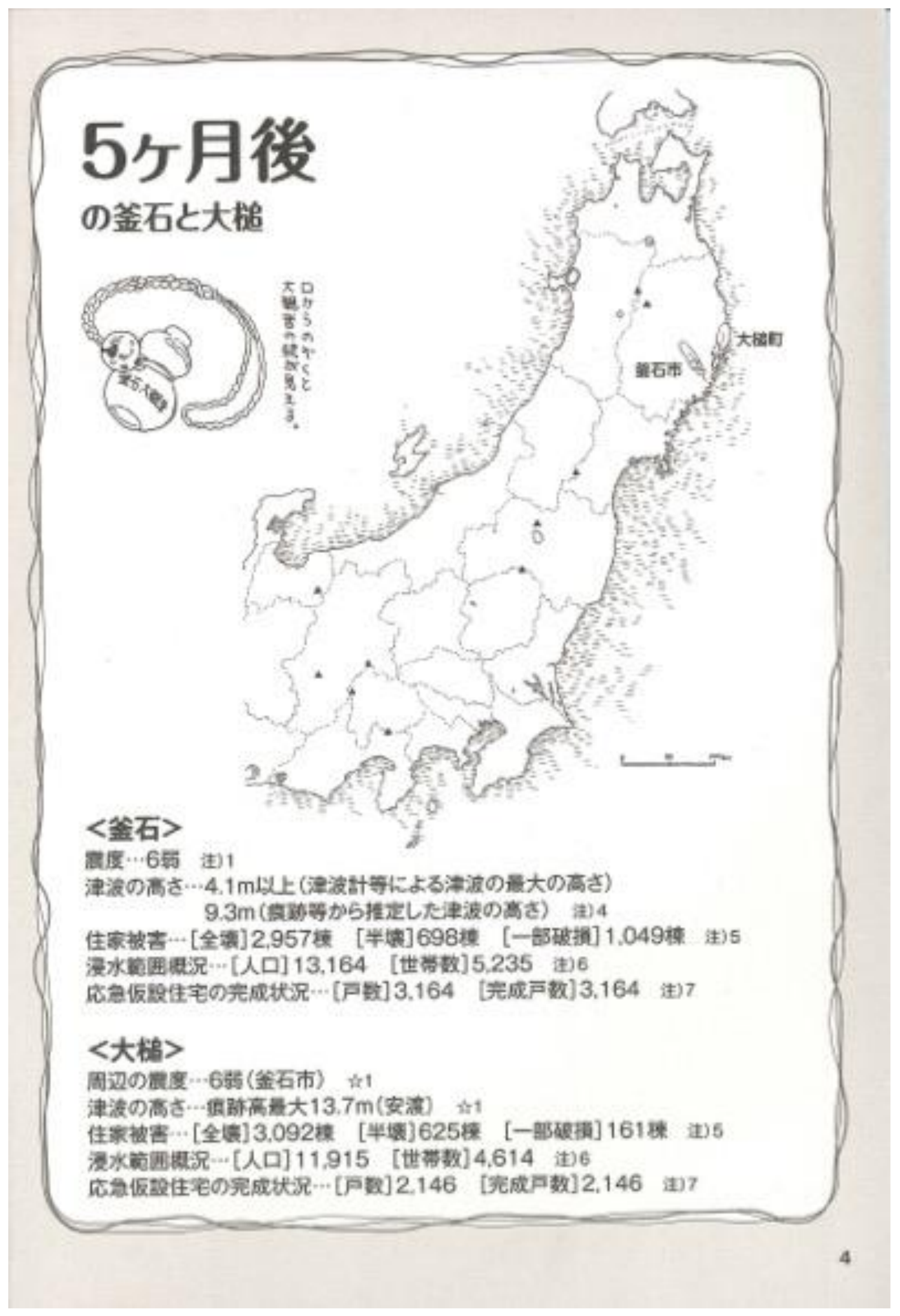


Figure 2: Fumiyo Kouno. Hi no tori 2, 2016. Comic. Page 127. (C) Fumiyo Kouno/NIHONBUNGEISHA "HINO-TORI 2".

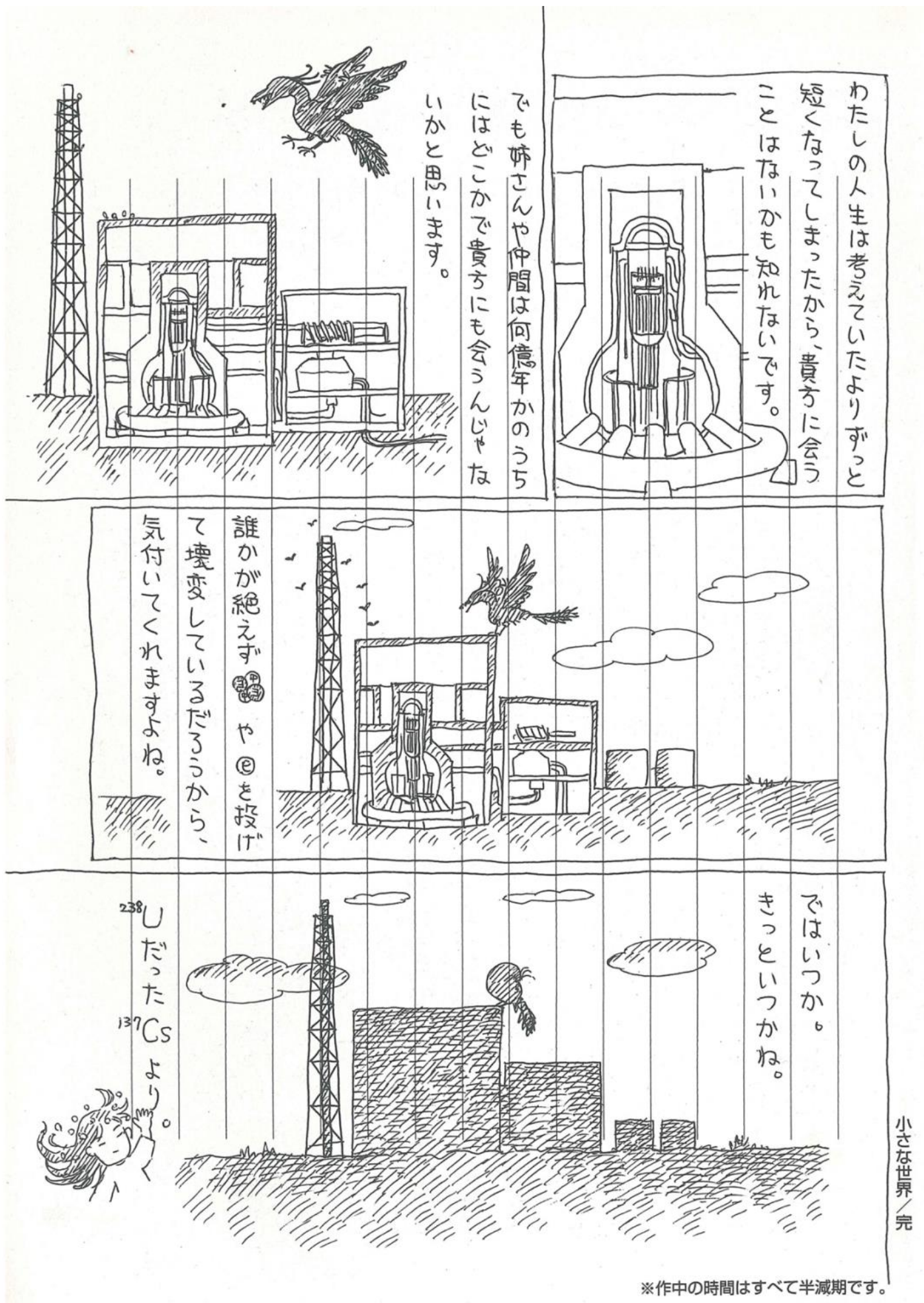


Figure 3: Fumiyo Kouno. Hi no tori, 2014. Comic. Front and back cover art (beneath book jacket). () Fumiyo Kouno/NIHONBUNGEISHA "HINO-TORI".

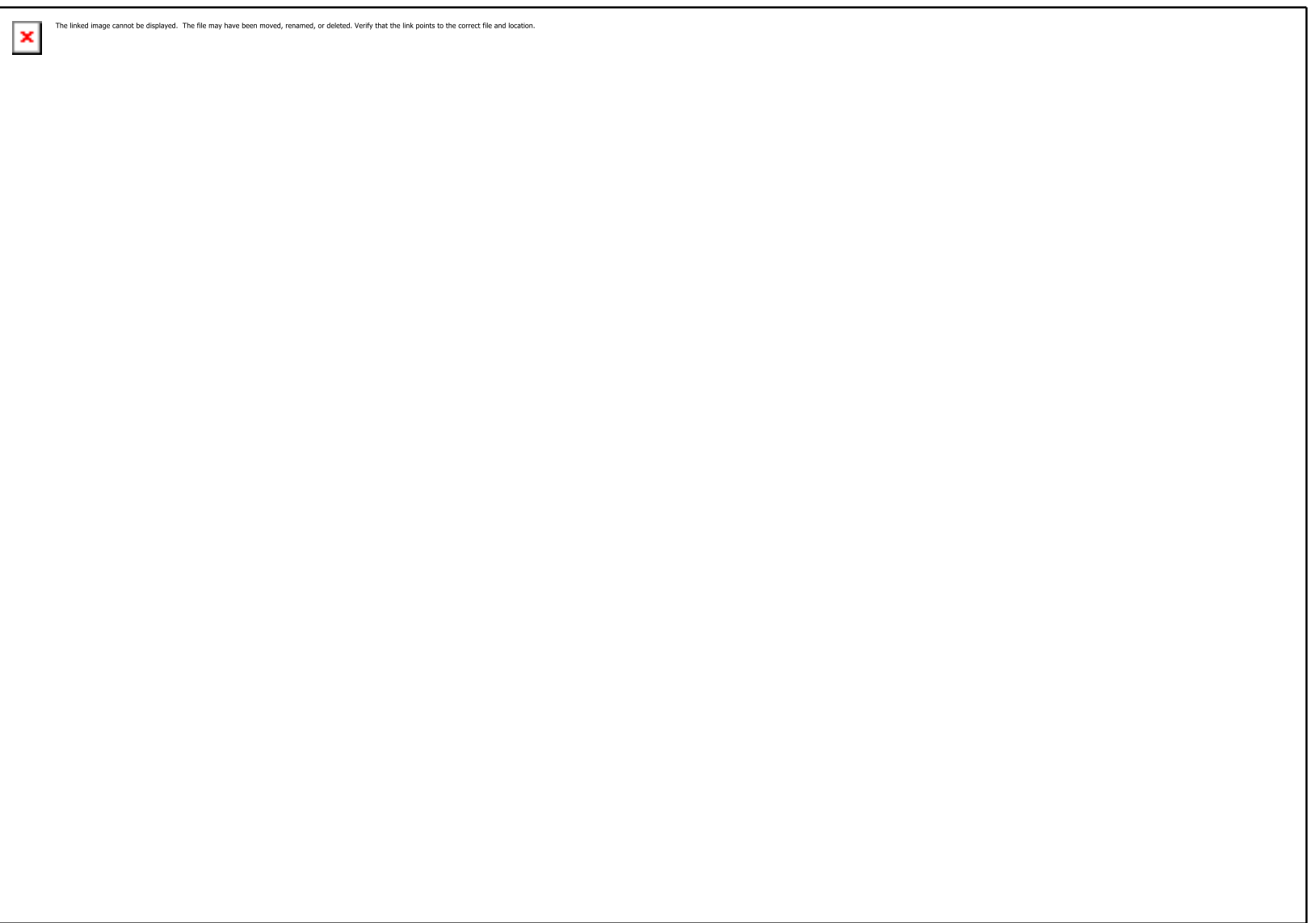


'In Japanese the stadium is called the 'Kamaishi Unosumai Fukkō Sutajiamu', and the stadium's website gives the English name of the stadium as the 'Kamaishi Unosumai Memorial Stadium'. It is noteworthy that the original Japanese name of the stadium includes the word ' $f u k k \bar{o}$ ' (recovery or reconstruction). In English the stadium has also been referred to as the 'Kamaishi Recovery Memorial Stadium'.

ii Nakazawa Keiji’s Hadashi no Gen was serialized in the magazine Shūkan Shōnen Janpu (Weekly Jump) from 1973-1985.

iii Art Spiegelman's Maus was serialized in the magazine Raw from 1980 to 1991.

${ }^{\text {iv }}$ Here, I use the 'single scene manga' (instead of 'single-frame manga') to translate 'hito koma manga' as other than the supplementary manga, in Hi no tori Kouno's drawings are not contained within a frame.

" Shiriagari's 'Kibē' is included in collection Ano hi kara no manga: 2011.3.11 (Manga Ever Since: 2011.3.11, 2011). In his manga, he portrays elements and isotopes as family members (Shiriagari 2011: 57-72).

vi See also Jacqueline Berndt's discussion of Shiriagari's 'Hope' (Berndt 2013: 73).

${ }^{\text {vii }}$ Tezuka's twelve-volume series Hi no tori moves backwards and forwards in time, spanning prehistoric times and the future. Completion of the seraies was cut short by the artist's death in 1989.

viii Given the prominence of Tezuka's Hi no tori in the world of manga, it is also possible to read Kouno's Hi no tori as a play on the Tezuka's Phoenix. Tezuka's manga was a long-running series that remained unfinished at the time of his death, so Kouno's Hi no tori might suggest the longevity of radioactivity and its continuous impact on humans and the environment for years after March 11, 2011.

${ }^{\text {ix }}$ Morimatsu Akiko has delivered speeches at the United Nations World Conference on Disaster Risk (March 2015) in Sendai, Japan and at the 'Remember Fukushima Parliamentary Public Meeting' in the House of Commons (March 2019) in Westminster, London. 